\title{
Shearing Rate Effects On Research Centre For Soft Soils (Recess) Clay Using Cone Penetration Test (CPT)
}

\author{
Azranasmarazizi Ayob1, a , Nor Azizi Yusoff',b , Ismail Bakar,c, \\ Nur Abidah Azhar ${ }^{4, d}$, Ameer Nazrin Abd Aziz ${ }^{5, e}$ \\ 1,2,3,4,5 Infrastructure and Geomatic Engineering Department,Faculty of Civil Engineering and \\ Environmental, \\ Universiti Tun Hussein Onn Malaysia,86400 Parit Raja, Batu Pahat Johor, Malaysia \\ aazran.ayob@gmail.com, bazizy@uthm.edu.my, 'bismail@uthm.edu.my \\ deida.azhar@gmail.com, eameernazrinaziz@yahoo.com
}

Keyword : Keyword: Speed of penetrations, CPT, Mackintosh probe, rate effect, shear strength

\begin{abstract}
A wide range of industrial applications, on land and offshore, require the solution of time domain problems and an associated understanding of rate effects in clay soils. In recent decades many researchers have examined the correlation between shear strength of soils and variation of shear strain rate and it is generally accepted that the strength increases by $1-5 \%$ for each order of magnitude increase in shear strain rate. This paper discusses the effects of penetration rate on the penetration resistance $\left(q_{c}\right)$ by using cone penetration test (CPT) test setup. The research had been conducted at RECESS and cone penetration test were used in three selected range of rate which were $0.5 \mathrm{~cm} / \mathrm{s}, 1 \mathrm{~cm} / \mathrm{s}$ and $5 \mathrm{~cm} / \mathrm{s}$. In addition, Mackintosh probe test had been considered as comparison with CPT test for the unconfined compressive strength. The result shows different penetration rate influenced the soil shear strength. For the slowest rate $(0.5 \mathrm{~cm} / \mathrm{s})$, the shear strength was approximately $0.15 \%$ less compared to the standard rate $(2 \mathrm{~cm} / \mathrm{s})$. However, for the highest rate $(5 \mathrm{~cm} / \mathrm{s})$, the shear strength was $0.22 \%$ more than the reference rate $(0.5 \mathrm{~cm} / \mathrm{s})$. In conclusion, it is suggested that the RECESS clay soil influenced by the rate effect and in agreement with previous research findings.
\end{abstract}

\section{Introduction}

The accuracy and detailed nature of CPT data become the principal reasons for acceptance and increased use of the CPT in recent years. The fact that the test is conducted in-situ eliminating sample disturbance and changed stress conditions, and the relative speed and economy of the method as compared to conventional drilling and sampling [1]. The measurements of cone penetration test can effectively be used in many Geotechnical engineering applications such as stratification and identification and also to evaluate different soil properties such as strength and consolidation characteristics of the soil. For this study, CPT tests were conducted by having different speed of penetrations in order to investigate the rate effect for soft soil deposit in RECESS, UTHM, Batu Pahat, Malaysia.

\section{Literature Review}

Cone penetration test CPT test is a faster, repeatable and economical option in conducting site investigation compared to other conventional method. Based on BS 1377-9:1990, CPT method covers the determination of the resistance of soils in situ thru continuous penetration. In addition, it also capable tocontinuously measures or at selected depth intervals the penetration resistance of the cone. If required, the local friction resistance on a sleeve friction, $\left(f_{s}\right)$ and pore pressure in the vicinity of the cone and sleeve could be investigated [2].

Previous Case Study on Rate Effect Variable rates of penetration had beenconducted in many types of soils such as in clay, sand, silty soils and also in intermediate soils. In cone penetration test, the standard rate of penetration is $2 \mathrm{~cm} / \mathrm{s}[3,4,5,6]$. There were many research utilised different 
speed of penetration $[7,8,9,5,6,10,11]$ whether in high or slow speed in cone penetration testing. Different speeds of penetration will give different influence to cone resistance $\left(q_{c}\right)$, sleeve friction $\left(f_{s}\right)$ and also porewater pressure $(u)$.

The researcher has investigated the effects of drainage during penetration [4]. Penetration tests were performed with various velocities in the field and in a calibration chamber. It was found that the higher the penetration rate is, the larger the undrained shear strength $\left(s_{u}\right)$ is, and the larger the $q_{c}$. The finding was inline with [11]. They found that at very high rates of penetration, where conditions are fully undrained, the resistance increases with increasing velocity due to viscous effects.
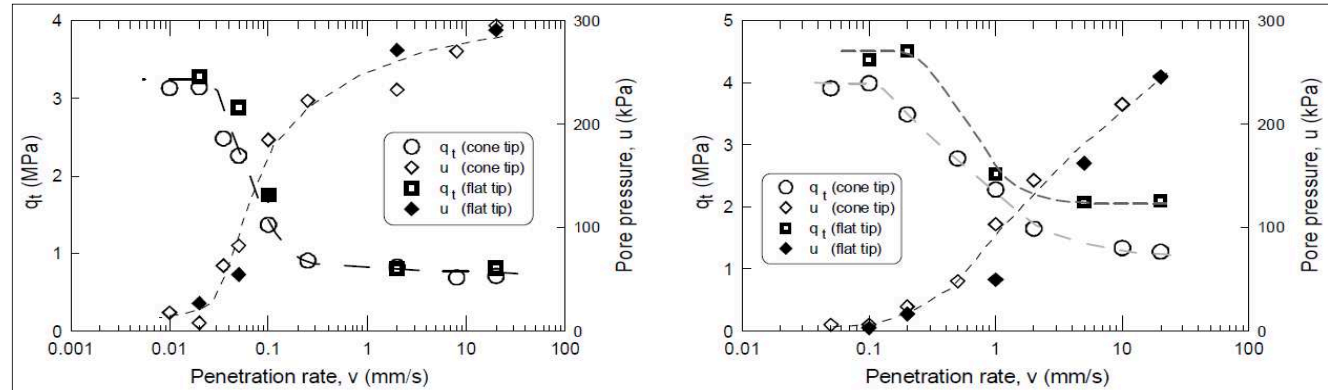

Fig.1: Effect of penetration rate on $q_{t}$ and pore pressure for $(a)$ specimen P1 and (b) specimen P2.

Methodology

CPT Penetrometer For this study, a basic cone penetrometer with $35.4 \mathrm{~mm}$ base diameter, $10 \mathrm{~cm}^{2}$ projected area and $60^{\circ}$ cone angles was implemented. The cone had been pushed into the ground at different rates of penetration which are $0.5 \mathrm{~cm} / \mathrm{s}, 2 \mathrm{~cm} / \mathrm{s}$, and $5 \mathrm{~cm} / \mathrm{s}$ respectively. The cone, were connected to $1 \mathrm{~m}$ long hollow drill rods as shown in Fig. 2 which acting as a tubular pipe pile.

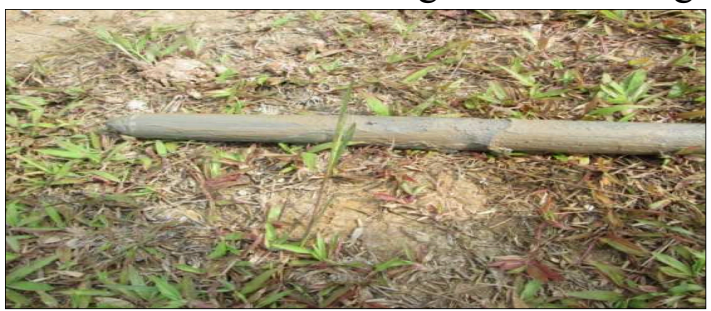

Fig.2: The tubular pipe pile model

Field testing at RECESS The test has been conducted at RECESS UTHM as shown in Fig. 3 and Fig. 4. A model pile was used to represent the actual pile on site. For cone penetration test (CPT) the pile was penetrated into the soil approximately about $4.6 \mathrm{~m}$ depth. On the other hand, Mackintosh probe was conducted at the same test site up to $9 \mathrm{~m}$ depth. The cone resistance $\left(q_{\mathrm{c}}\right)$ for $\mathrm{CPT}$ and probe blows from the operation had been monitored and recorded as shown in Fig. 3 and Fig.4.

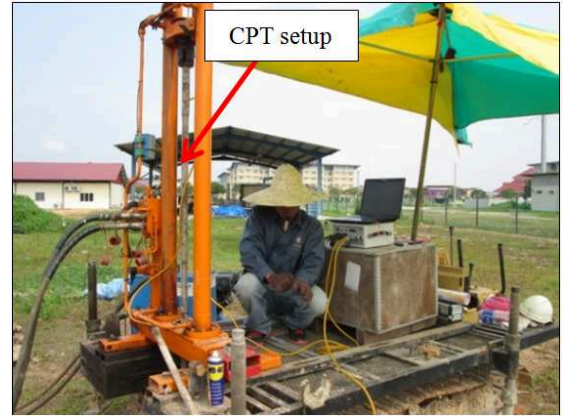

Fig.3: Cone penetration testing operation

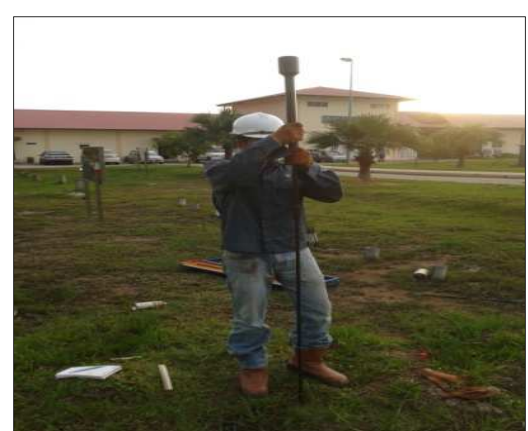

Fig.4. Mackintosh probe operation

Result and Discussion This chapter is focused on the analysis and discussion from the field monitoring test conducted at RECESS, UTHM. The shear strength and bearing capacity for cone penetration test and Mackintosh probe test had been compared. 
Field monitoring data From the field monitoring, the results are as shown in Fig. 5 and Fig. 6. From the data obtained in Fig. 5, there are 3 different rate of penetrations were applied. Each rate was penetrated into soils constantly at the designated speed to ensure the accuracy of data analysis.

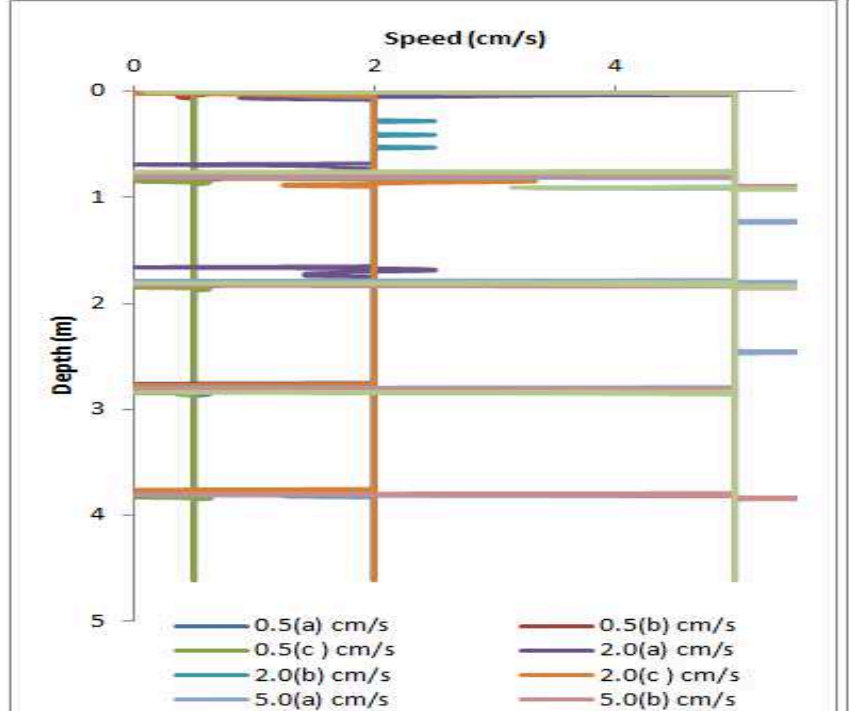

Fig.5 Different penetration speed

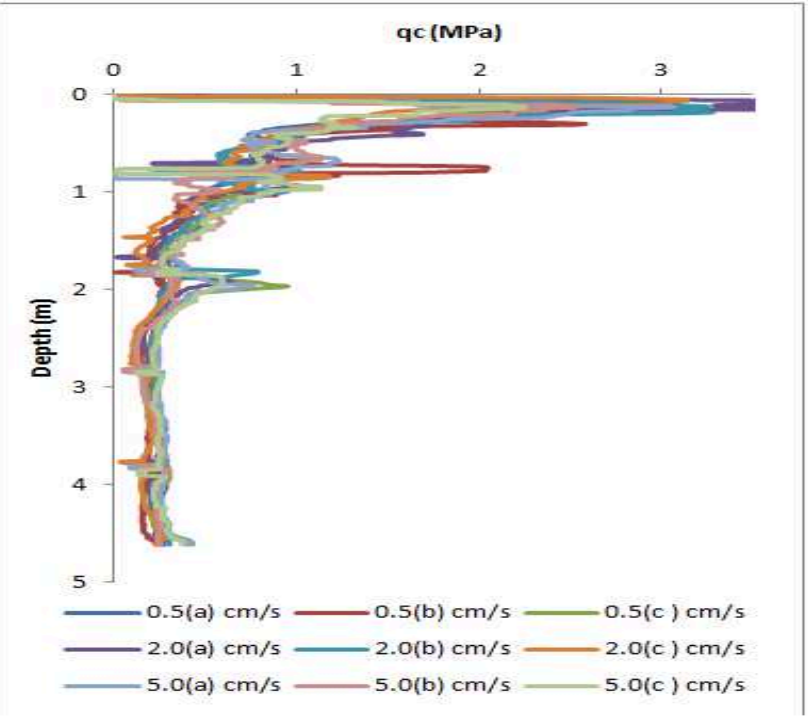

Fig.6Cone resistance varies with depth

Rate effect analysis Fig.7, 8 and 9 show some analysis of rate effect of soil at RECESS UTHM. It was found that the cone resistance was increases when higher speed of soundings performed for the CPT.

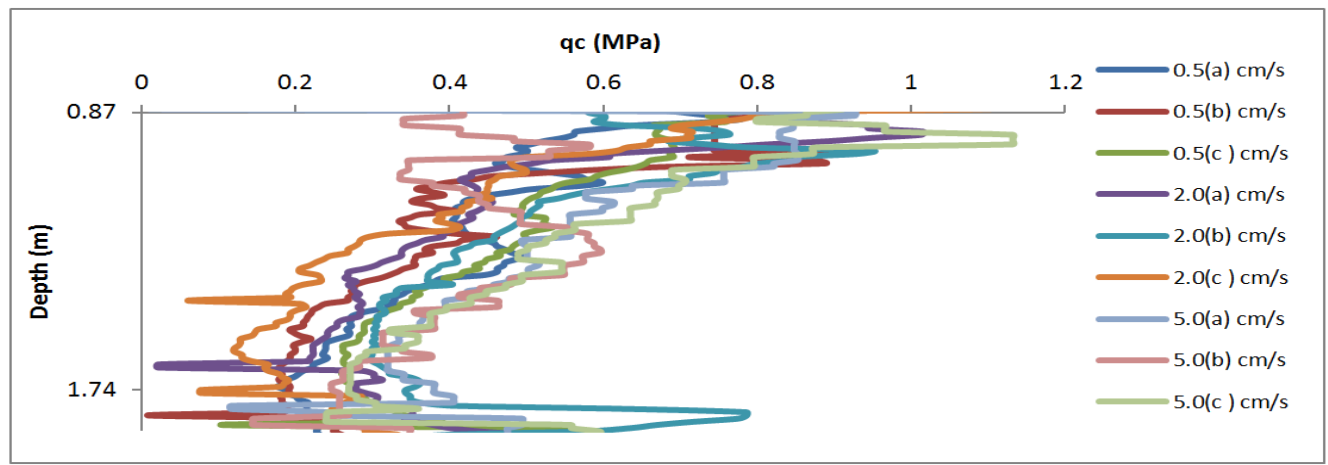

Fig.7 Rate effect at $0.87 \mathrm{~m}$ to $1.87 \mathrm{~m}$ depth

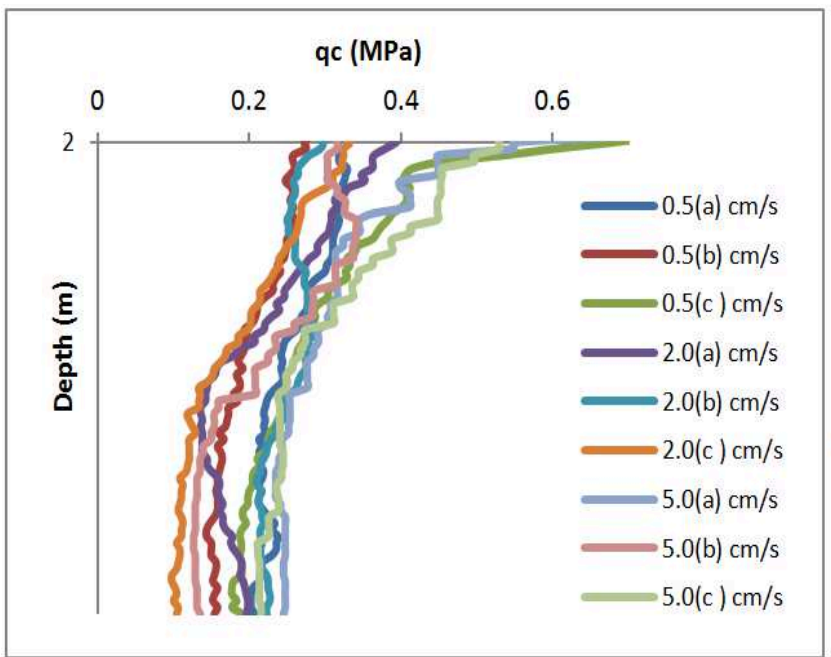

Fig. 8 Rate effect at $2.01 \mathrm{~m}$ to $2.73 \mathrm{~m}$ depth

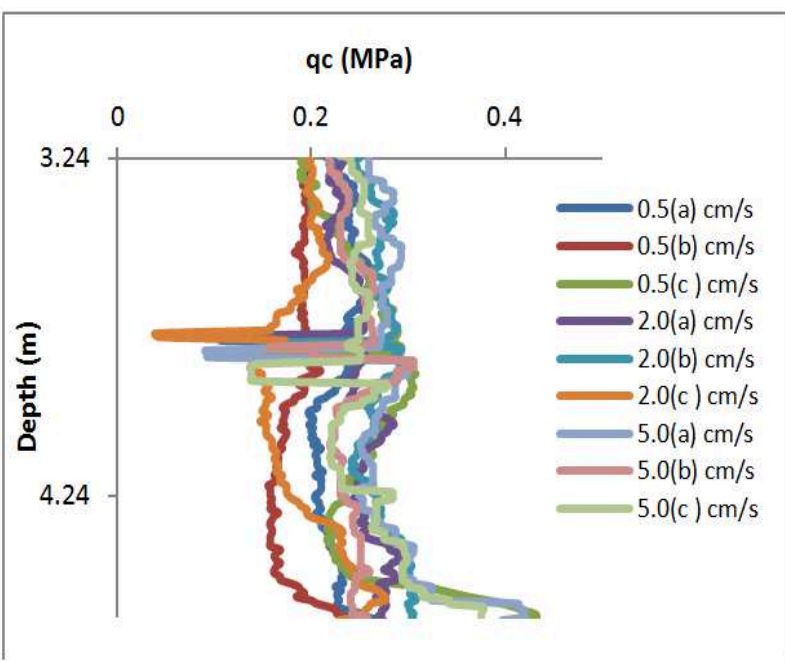

Fig.9 Rate effect at $3.24 \mathrm{~m}$ to $4.61 \mathrm{~m}$ depth 
CPT analysis Based on this study, the percentage different of cone resistance, $\left(q_{c}\right)$ for $0.5 \mathrm{~cm} / \mathrm{s}$ which are the lowest speed and the highest speed which $5.0 \mathrm{~cm} / \mathrm{s}$ is about $0.22 \%$. The percentage different for $0.5 \mathrm{~cm} / \mathrm{s}$ with $2.0 \mathrm{~cm} / \mathrm{s}$ is about $0.15 \%$ while the percentage different for $2 \mathrm{~cm} / \mathrm{s}$ with 5 $\mathrm{cm} / \mathrm{s}$ is about $0.06 \%$. Based on previous research [11], the scenario may be due to soil viscous effect. In conclusion, faster speed of penetration influence greater cone resistance.

Mackintosh probe analysis In order to clarify the condition in the previous section, a simple approach by utilizing Mackintosh probe test had been conducted. The results are as shown in Fig. 10(a) at B2, 10(b) at B5 and 10(c) at D5. It can be observed that the soil layer is harder for the first $1 \mathrm{~m}$ depth.

In comparison, the soil strength from Mackintosh probe was lower than the CPT data. Anyway, for this particular study, it is appropriate enough to act as comparison. Further elaboration may be required to fully understand the scenario.
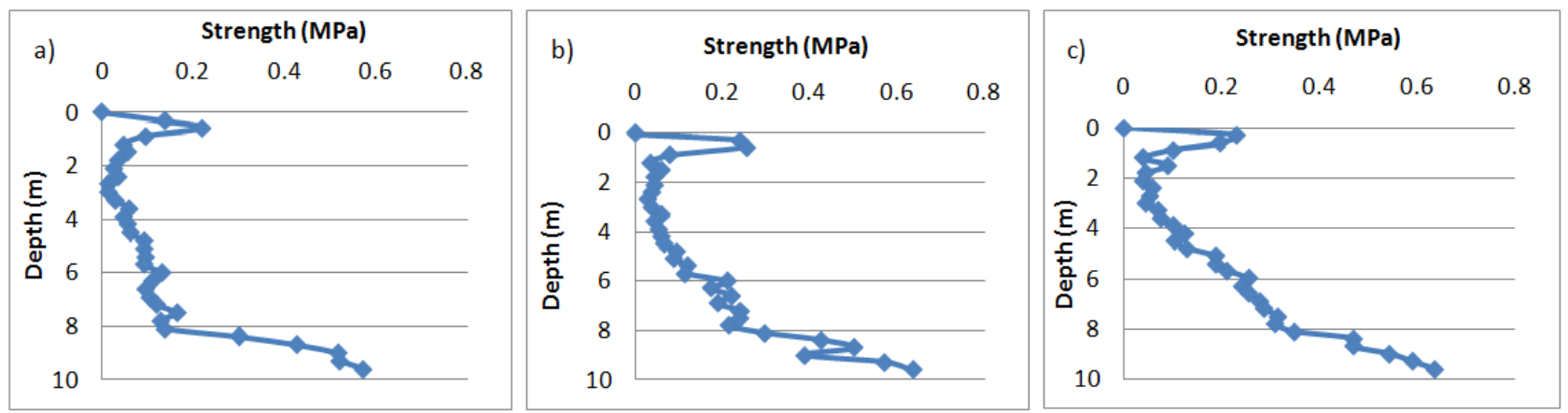

Fig.10: Soil strength based on Mackintosh probe test

\section{Conclusion}

The results obtained from this study may be a platform for comparison between the standard speed of penetration of CPT with slower and higher speed of penetration. Each imposed speed will give a different reading on the cone resistance in which showing a rate effect problems. When the speed of $0.5 \mathrm{~cm} / \mathrm{s}$ was imposed, cone resistance recorded a lower reading than the higher speed of which are $5 \mathrm{~cm} / \mathrm{s}$. The percentage different is about $0.22 \%$. The percentage different for $0.5 \mathrm{~cm} / \mathrm{s}$ with $2.0 \mathrm{~cm} / \mathrm{s}$ are $0.15 \%$ while percentage different for $2.0 \mathrm{~cm} / \mathrm{s}$ with $5.0 \mathrm{~cm} / \mathrm{s}$ is about $0.06 \%$. In addition, the cone resistance increases with the increasing penetration velocity possibly due to viscous effects [11].

\section{Acknowledgement}

I would like to give thanks UTHM GIPS 1363 for funding this research. Thank you too to my supervisors, Dr. Nor Azizi bin Yusoff and Prof. Emeritus Dato' Haji Ismail bin Haji Bakar for their guidance, my friends, Nur Abidah binti Azhar and Ameer Nazrin bin Abd Aziz who's helping me throughout this research. Lastly, thanks to my family whom give me support for me to finish this research.

\section{References}

[1] R. Yilmaz, Advances in Cone Penetrometer Technology, (2013).

[2] A.-L. T. Adrian-Traian Iliesi, Use of Cone Penetration Test and Cone Penetration Test with Porewater Pressure Measurement for Difficult Soil Profiling, (2012).

[3] M. B. Jaksa, W. S. An Improved Technique for Evaluating the CPT Friction Ratio, (2000).

[4] M. P. Kwang Kyun Kim, Interpretation of Cone Penetration tests in Cohesive Soils. Technology Transfer and Project Implementation Information, (2006). 
[5] M. S. Trevisan, Influence of rate of penetration on CPT tip resistance in standard CPT and in CPTWD (CPT while drilling). 2nd International Symposium on Cone Penetration Testing, (2010).

[6] Jr., J. G. Tom Rate and State Effects on Cavity Expansion in a Modified Cam-Clay Medium Using FLAC, (2010).

[7] Kenneth A. Sudduth, J. W. Evaluation of A Soil Conductivity Sensing Penetrometer. An ASAE Meeting Presentation, (2000).

[8] D. K. Kim, Effect of Penetration Rate and Filter Location on Piezocone Test Results. 273279, (2004).

[9] M. F. Shin Fun Chung, Effect of Penetration Rate on Penetrometer Resistance in Clay, (2006).

[10] B. N. Rikke Poulsen, Field Cone Penetration Tests with Various Penetration Rates - Test Results, (2011).

[11] José R. M. S. Oliveira, M. S., \& Almeida, a. M. Influence of Penetration Rate on Penetrometer Resistance. American Society of Civil Engineers, (2011).

[12] K. Kim, Prezzi, M., Salgado, R., \& Lee, A. W. Effect of Penetration Rate on Cone Penetration Resistance In Saturated Clayey Soils. Journal of Geotechnical And Geoenvironmental Engineering (C) Asce / August 2008, 1142-1153. 